Original Article

\title{
Unnoticed surgical gloves perforation: A multicentric study of the leading factors.
}

Medhioub Fatma 1,2, ${ }^{*}$, Jaber Eya 1,2, Hamrouni Anouar 1,2, Gharbi Lassad 1,2.
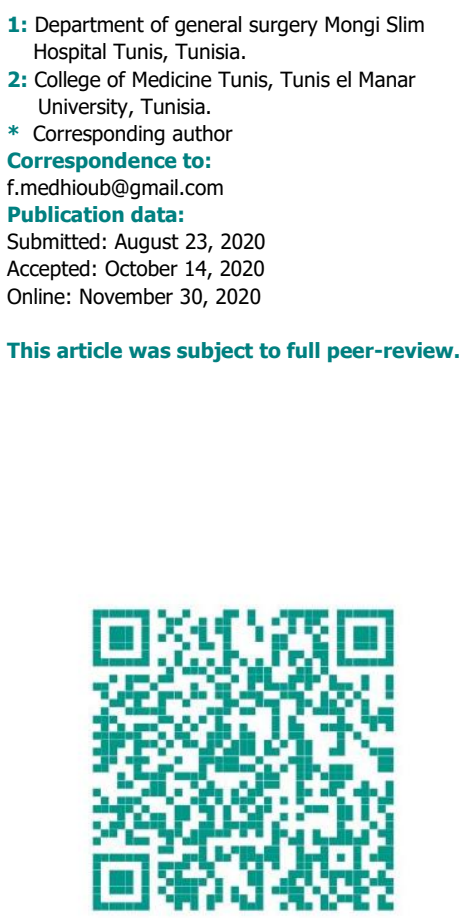

This is an open access article distributed under the terms of the Creative Commons Attribution NonCommercial License 4.0 (CCBY-NC) allowing to share and adapt.

Share: copy and redistribute the material in any medium or format.

Adapt: remix, transform, and build upon the licensed material.

the work provided must be properly cited and cannot be used for commercial purpose.

\section{Abstract:}

\section{Background}

Surgical gloves act as protective barrier against blood-borne pathogens transmission from patients to healthcare workers and vice versa. The aim of this study was to assess the rate of surgical gloves intraoperative perforation and to highlight its leading factors.

\section{Methods}

A descriptive cross-sectional multicentric study was conducted at three different Tunisian university hospitals: Charles Nicolle, La Rabta and Mongi Slim. Four different surgical departments were involved: cardiovascular surgery, urology, general surgery and otorhinolaryngology. The gloves were collected and tested immediately at the sterilization units using the leak test as described in European Norm EN 455-1.19. Results were produced using the statistical package for social sciences version 19.0 and the X2 was used with a significance threshold of $5 \%$.

\section{Results}

A total of 320 gloves were collected. Seventy-two were found to be perforated $(22.5 \%)$. The majority of the perforated gloves were collected after cardiovascular procedures $(40 \%, \mathrm{p}=0.001)$, on the non-dominant hand $(71 \%, p=0.0001)$, when the duration of the procedure exceeded 90 minutes $(p=0.0001)$ and for thinner gloves $(61 \%, p=0.018)$. The left index finger of the surgeon's glove is more likely to be perforated $(38 \%)$.

\section{Conclusion}

This study showed considerable gloves perforation rate during surgical procedures that could indicate the implementation of new rules and policies in the operating theater practices.

Key words

Perforation, surgical gloves, operating theater, associated factors.

Citation: Medhioub F, Jaber E, Hamrouni A, Gharbi L. Unnoticed surgical gloves intraoperative perforation: A multicentric study of the leading factors. Jr. med. res. 2020; 3(3):9-12. Medhioub et al (c) All rights are reserved.

https://doi.org/10.32512/jmr.3.3.2020/9.12

Submit your manuscript: www.jmedicalresearch.com 


\section{Introduction}

Gloves were first recommended for medical staff as a protection from chemical products [1]. Since early $80^{\mathrm{S}}$ surgical gloves were recognized as protective barrier against blood-borne pathogen transmission and their single use was recommended [2].

Gloves perforation occurs frequently during surgical procedures [3]. This incident may expose both patient and the surgical staff to various infections. As perforation may not be apparent, it seems useful to understand its mechanisms and the leading circumstances. This could minimize the infection risk for the patients and the health practitioners.

Our study aims to determine the rate of glove perforation and the contributing factors.

\section{Materials and Methods}

Study design

This study is descriptive, cross-sectional and multicentric. It was conducted in 4 different surgical units for 3 months (Tunis, Tunisia):

*Department of urology ,Charles Nicolle hospital

*Department otorhinolaryngology, Charles Nicolle hospital

* Department of cardiovascular surgery, La Rabta hospital

*Department of general surgery, Mongi Slim hospital.

\section{Population}

This study included surgeons, residents, operating room technicians and scrub nurses. The study included all gloves used by the participants during the different surgical procedures. We have tested two different brands of gloves made from natural rubber latex (A and $B$ ). The brand $A$ glove thickness was $0.20 \mathrm{~mm}$ and the brand $B$ glove thickness was $0.16 \mathrm{~mm}$.

\section{Data collection}

Members of the surgical teams included were asked to fill out a brief questionnaire about age, gender, function, years of experience and dominant hand. All gloves were collected in a plastic bag labeled according to the type of the procedures, duration of the glove's use, position of member and the dominant hand for activity. The characteristics of the glove's brand were collected for each participant.

The gloves were collected and tested immediately at the sterilization units using the leak test as described in European Norm EN 455-1.19. Each Glove was evaluated separately. A 50$\mathrm{mm}$-diameter tube made of polyvinyl chloride is inserted vertically into the glove and fixed with a ring positioned at $40 \mathrm{~mm}$ from the end to avoid glove damage. One liter $(+/-50 \mathrm{ml})$ of water is poured into the glove. The glove was immediately inspected for 23 minutes to detect any leakage. The number and location of perforations as well as participant's perception were noted.

\section{Data analysis}

Data was entered and analyzed using the Statistical Package for Social Sciences (SPSS) version 19.0. The Chi-square test (X2) was used for the comparative study. Significance was retained for $P$
value $<0.05$. Results were presented in the form of tables and graphics using Microsoft Excel 2007.
Bibliographic review

We reviewed literature using several search engines and databases: Pub Med, Science Direct, EM consult, google scholar using these keywords: Perforation, surgical gloves, operating theater, associated factors. Twenty-eight relevant papers published over the past fifteen years were collected from the literature.

Ethical considerations

This study was approved by all the ethical committees of the participating centers.

\section{Results}

Our study included 320 gloves. The participants $(n=87)$ were residents in $38 \%$ of cases, senior surgeons in $29 \%$, operating room technicians in $26 \%$ and scrub nurses in $7 \%$. There was a male predominance with a sex ratio of 2.5. Most of the participants were $<30$ years old. The professional experience was $<5$ years in $47 \%$ of cases. Most of the participants were right-handed (94\%). (Table 1).

\begin{tabular}{|c|c|c|}
\hline Characteristics & $n$ & $\%$ \\
\hline \multicolumn{3}{|l|}{ Gender } \\
\hline Male & 63 & 72.4 \\
\hline Female & 24 & 27.6 \\
\hline \multicolumn{3}{|l|}{ Age } \\
\hline $20-30$ & 47 & 54 \\
\hline $31-40$ & 12 & 13.8 \\
\hline 41-50 & 17 & 19.5 \\
\hline$>50$ & 11 & 12.6 \\
\hline \multicolumn{3}{|l|}{ Surgical specialty } \\
\hline Cardio-vascular & 20 & 23 \\
\hline General and digestive & 26 & 29.9 \\
\hline Urology & 17 & 19.9 \\
\hline Otorhinolaryngology & 24 & 27.6 \\
\hline \multicolumn{3}{|l|}{ Position } \\
\hline Surgeon & 25 & 28.7 \\
\hline Resident & 33 & 37.9 \\
\hline Surgical technician /scrub nurse & 29 & 33.4 \\
\hline \multicolumn{3}{|l|}{ Years of experience } \\
\hline 1-5 & 41 & 47.1 \\
\hline 6-10 & 26 & 29.9 \\
\hline$>10$ & 20 & 23 \\
\hline \multicolumn{3}{|l|}{ Dominant hand } \\
\hline Right & 82 & 94.3 \\
\hline Left & 5 & 5.7 \\
\hline
\end{tabular}

The gloves usage characteristics is summarized in Table 2.

The overall perforation rate was $22.5 \%(n=72)$. Eighty different perforations were noted. The most perforated finger was the index finger (34\%). Perforation was located in the thumb in $25 \%$ of cases, in the ring finger in $14 \%$ and the little finger in $11 \%$. Most of the perforations occurred in the non-dominant hand (left hand). 
Unnoticed surgical gloves intraoperative perforation: A multicentric study of the leading factors.

Table 2: glove usage characteristics

\begin{tabular}{|lcc|}
\hline Variables & $\mathbf{n}$ & \% \\
\hline Surgical specialty & & \\
\hline Cardio-vascular & 78 & 24.4 \\
\hline General and digestive & 79 & 24.7 \\
\hline Urology & 86 & 26.9 \\
\hline Otorhinolaryngology & 77 & 24.1 \\
\hline Position & & \\
\hline Surgeon & 94 & 29.4 \\
\hline Surgical resident & 129 & 40.3 \\
\hline Surgical technologist and scrub nurse & 97 & 30.3 \\
\hline Procedure duration & & \\
\hline$<90$ & 207 & 64.7 \\
\hline$>90$ & 113 & 35.3 \\
\hline
\end{tabular}

The perforation rate was $67 \%(n=48)$ after procedures that exceeded 90 minutes $(p=0.0001)$. Senior surgeons had the highest perforation rate $(42 \%)$. Forty percent of the perforations occurred during cardio-vascular procedures. Table 3 summarized the perforations associated factors

Table 3: Glove perforation associated factors

\begin{tabular}{|c|c|c|c|}
\hline Associated factor & Perforated glove & $\begin{array}{l}\text { Non-perforated } \\
\text { glove }\end{array}$ & $\mathbf{P}$ \\
\hline Duration & & & 0.0001 \\
\hline$<90$ & $24(33.3 \%)$ & $183(73.79 \%)$ & \\
\hline$>90$ & $48(66.6 \%)$ & $65(26.21 \%)$ & \\
\hline Surgical specialty & & & 0,001 \\
\hline Cardio-vascular & $29(40.28 \%)$ & 49 (91.76\%) & \\
\hline General and digestive & $19(26.39 \%)$ & $60(24.19 \%)$ & \\
\hline Urology & $14(19.44 \%)$ & $72(29.03 \%)$ & \\
\hline Otorhinolaryngology & $10(13.89 \%)$ & $67(27.02 \%)$ & \\
\hline Participant's function & & & 0.49 \\
\hline Surgeon & $30(41.66 \%)$ & $105(42.34 \%)$ & \\
\hline Surgical resident & $24(33.34 \%)$ & 64 (25.81\%) & \\
\hline $\begin{array}{l}\text { Surgical technologist or scrub } \\
\text { nurse }\end{array}$ & $18(25 \%)$ & $79(31.85 \%)$ & \\
\hline Hand dominance & & & 0.0001 \\
\hline Dominant hand & $21(29.17 \%)$ & $139(56.05 \%)$ & \\
\hline Non-dominant hand & $51(70.83 \%)$ & 109 (43.95\%) & \\
\hline Thickness & & & 0.001 \\
\hline Brand A & $28(38.8 \%)$ & $135(54.4 \%)$ & \\
\hline Brand B & $44(61.2 \%)$ & $113(45.6 \%)$ & \\
\hline Powder & & & 0.018 \\
\hline Powdered & $56(77.8 \%)$ & $222(89.52 \%)$ & \\
\hline Powder-free & $16(22.2 \%)$ & $26(10.48 \%)$ & \\
\hline
\end{tabular}

\section{Discussion}

This study investigated the frequency of unnoticed surgical glove perforation at 3 different Tunisian university hospitals in 4 different surgical specialized units. It revealed a perforation rate of $22,5 \%$. According to the literature, this rate varies from 8 to $61 \%$ [4]. The results reported by Tlili et al were comparable with a rate of $16,5 \%$. However, a higher perforation rate of $52 \%$ was shown by Goldman et al $[3,5]$.
The variability in these results may be explained by the difference in specialties, instrumentation, experiences and working conditions. One of the main issues encountered is the lack of perforation perception before the end of the procedure.

Glove perforation can expose both patients and surgical team members to considerable risks. It may increase the incidence of patient's nosocomial infections specially those caused by Staphylococcus Aureus. The practitioners maybe exposed to viral blood-borne diseases such as AIDS and Hepatitis [6]. The perforation remains unnoticed usually until the end of the procedure. This makes mandatory the identification of associated factors. These factors are related to the surgical procedure, the practitioner, and the glove itself. Gloves perforation is more common in orthopedic surgery than in soft tissue procedure [7].

The use of power tools, handling sharp bones and working in deep cavities could contribute more to glove perforation in orthopedic procedures [8]. It was reported in a study that the rate rises to $67 \%$ during a hip arthroplasty closure and with the use of cone-shaped needles [9].

In our study, the rate of perforation was significantly higher in cardio-vascular surgical procedures (40.3\%) and in the senior surgeon's gloves (41.7\%). Other studies had the same findings [10-13]. This high rate is explained by the fact that surgeons are the first users of instruments and that the manipulation of instruments and implants increases the risk of perforation $[14,15]$.

Our study found that $70.8 \%$ of perforations are detected on the non-dominant hand. These findings are comparable to those revealed by some other authors $[17,18]$. The surgeon's index finger and thumb seem to be the site of predilection for glove perforation. [19].

Regarding the duration of the procedure, all authors agreed that the risk of unnoticed glove perforation is significantly higher for long and complex procedures. Our study showed a cut-off point at 90 minutes concurring with the findings of several other studies [20-22]. We have tested in two different brands of gloves ( $A$ and $B$ ) made from natural rubber latex. Brand $A$ gloves are thicker than brand $B$ gloves. We found significant higher perforation rate in the thinner brand. The glove characteristics may interfere with the perforation rate.

The optimized air and waterproofness as well as the balanced elasticity could ensure the barrier glove's role and minimize perforation risk [23].

The powder reduces the friction between the hand and the glove's wall. However, hand perspiration during long procedures may increase powder temperature and lead to microperforations [24]. Some authors recommended "double" gloving to prevent perforation and to optimize protection. Concordant studies showed that the inner glove is exceptionally perforated. The implementation of double

Citation: Medhioub F, Jaber E, Hamrouni A, Gharbi L. Unnoticed surgical gloves intraoperative perforation: A multicentric study of the leading factors. Jr. med. res. 2020; 3(3):9-12. Medhioub et al (c) All rights are reserved. 
Unnoticed surgical gloves intraoperative perforation: A multicentric study of the leading factors.

gloving concept is sometimes difficult. It may reduce the precision of the movements according to some surgeons and may increase the cost of procedure consumables [25-28].

Our study identified a considerable issue in the daily surgical practice. The rate of the unnoticed surgical team gloves perforation is high and may interfere with the procedure's outcomes. The four subspecialized surgical units involved are performing a high number of cases. To improve the quality and the safety of the procedures done, the implementation of some operating theater guidelines looks mandatory. The glove should be changed regularly in long procedures. More precaution should be taken for risky tasks. Our study is limited by the small population and this might be interfering with the statistics. The leading factors demonstrated might not be independent and must be proven in a larger series.

\section{Conclusion}

For some sophisticated surgical centers, the recommendation of systematic double gloving and frequent changing of gloves are reasonable. This could reduce the perforation rate and prevent its risks. We also suggest training sessions for the surgical team members in order to increase their awareness about the gravity of glove perforation and how to avoid the factors and circumstances that lead to higher perforation rate.

\section{Conflict of interest: None}

\section{References}

[1] Lee KP. Caroline Hampton Halsted and the origin of surgical gloves. J Med Biogr. 2020;28:64-66. [2] Schlich T. Why were surgical gloves not used earlier? Lancet. 2015;386:1234-5.

[3] Goldman AH, Haug E, Owen JR, Wayne JS, Golladay GJ. High Risk of Surgical Glove Perforation From Surgical Rotatory Instruments. Clin Orthop Relat Res. 2016 ; 474 :2513-17.

[4] Kang MS, Lee YR, Hwang JH, Jeong ET, Son IS, Lee SH, et al. A cross-sectional study of surgical glove perforation during the posterior lumbar interbody spinal fusion surgery : Its frequency, location, and risk factors. Medicine (Baltimore). $2018 ; 97: \mathrm{e} 10895$.

[5] Tlili MA, Belgacem A, Sridi H, Akouri M, Aouicha W, Soussi S, et al. Evaluation of surgical glove integrity and factors associated with glove defect. Am J Infect Control. 2018;46:30-33.

[6] Meakin LB, Gilman OP, Parsons KJ, Burton NJ, Langley-Hobbs SJ. Colored Indicator Undergloves [6] Meakin LB, Gilman OP, Parsons KJ, Burton NJ, Langley-Hobbs SJ. Colored Indicator Undergloves
Increase the Detection of Glove Perforations by Surgeons During Small Animal Orthopedic Surgery: A Increase the Detection of Glove Perforations by Surgeons

Randomized Controlled Trial. Vet Surg. 2016; 45:709-14.
[7] Lakomkin N, Cruz AI Jr, Fabricant PD, Georgiadis AG, Lawrence JTR. Glove Perforation in [7] Lakomkin N, Cruz AI Jr, Fabricant PD, Georgiadis AG, Lawrence JTR. Glove Perforation in
Orthopaedics: Probability of Tearing Gloves During High-Risk Events in Trauma Surgery. J Orthop Orthopaedics: Probability of

Trauma. 2018; 32:474-79.
[8] Sayin S, Yllmaz E, Baydur H. Rate of Glove Perforation in Open Abdominal Surgery and the [8] Sayın S, Yilmaz E, Baydur H. Rate of Glove Perforation in
Associated Risk Factors. Surg Infect (Larchmt). 2019; 20:286-91.

Associated Risk Factors. Surg Infect (Larchmt). 2019; 20:286-91.
[9] Lutsky KF, Jones C, Abboudi J, Kirkpatrick W, Liss F, Leinberry C, et al. Incidence of Glove [9] Lutsky KF, Jones C, Abboudi J, Kirkpatrick W, Liss F, Leinberry C, et al. Incidence
Perforation During Hand Surgical Procedures. J Hand Surg Am. 2017;42: 840.e1-840.e5.

[10] Li X, Li M, Li J, Gong W, Sun Y, Tang J, et al. Glove perforation and contamination in fracture fixation surgeries. Am J Infect Control. 2017; 45:458-60.

[11] Chan KY, Singh VA, Oun BH, To BH. The rate of glove perforations in orthopaedic procedures: single versus double gloving. A prospective study. Med J Malaysia. 2006; 61:3-7.

[12] Makama JG, Okeme IM, Makama EJ, Ameh EA. Glove Perforation Rate in Surgery: A Randomized, Controlled Study to evaluate the efficacy of double gloving. Surg Infect (Larchmt). 2016; 17:436-42 [13] Kim K, Zhu M, Munro JT, Young SW. Glove change to reduce the risk of surgical site infection or prosthetic joint infection in arthroplasty surgeries: a systematic review. ANZ J Surg. 2019; 89:100915.

[14] Egeler K, Stephenson N, Stanke N. Glove perforation rate with orthopedic gloving versus double gloving technique in tibial plateau leveling osteotomy: A randomized trial. Can Vet J. 2016; 57:115660.

[15] Goldman AH, Haug E, Owen JR, Wayne JS, Golladay GJ. High risk of surgical glove perforation from surgical rotatory instruments. Clin Orthop Relat Res. 2016; 474:2513-17.

[16] Guo YP, Wong PM, Li Y, Or PPL. Is double-gloving really protective? A comparison between the glove perforation rate among perioperative nurses with single and double gloves during surgery. Am J glove perforation rate am

Surg. 2012; 204:210-15.
[17] Partecke LI, Goerdt AM, Langner I, Jaeger B, Assadian O, Heidecke CD, Kramer A, Huebner NO. [17] Partecke LI, Goerdt AM, Langner I, Jaeger B, Assadian O, Heidecke CD, Kramer A, Huebner NO. Incidence of microperforation

Epidemiol. 2009; 30:409-14.
[18] Pérez-Serrano ME, Diniz-Freitas M, Fernández-Feijoo J, Limeres-Posse J. Glove perforations during routine dental hygienist procedures in a primary care setting. Aten Primaria. 2018; 50:130-31.
[19] Tao LX, Basnet DK. Study of Glove Perforation during Hip Replacement Arthroplasty: Its Frequency, Location, and Timing. Int Sch Res Not. 2014; 2014:1-5.

[20] Birnbach DJ, Thiesen TC, McKenty NT, Rosen LF, Arheart KL, Fitzpatrick M, et al. Targeted use of Alcohol-based hand rub on gloves during task dense periods: One step closer to pathogen containment by anesthesia providers in the operating room. Anesth Analg. $2019 ; 129: 1557-60$

[21] Wichmann T, Moriarty TF, Keller I, Pfister S, Deggim-Messmer V, Gautier E, Kalberer F, Koch PP, Wahl P. Prevalence and quantification of contamination of knitted cotton outer gloves during hip and knee arthroplasty surgery. Arch Orthop Trauma Surg. $2019 ; 139: 451-59$

[22] Enz A, Klinder A, Mittelmeier $H$, Kundt $G$, Mittelmeier W, Zaatreh S. Damages with High Consequences: Analysis of Perforations in Surgical Latex Operation Gloves from Orthopedic Surgeries. Eur J Microbiol Immunol (Bp). 2018; 8:159-62.

[23] Bardorf MH, Jäger $B$, Boeckmans E, Kramer A, Assadian O. Influence of material properties on gloves' bacterial barrier efficacy in the presence of microperforation. Am J Infect Control. 2016 Dec;44(12):1645-9.

[24] Martinez A, Han Y, Sardar ZM, Beckman L, Steffen T, Miller BS, et al. Risk of glove perforation with arthroscopic knot tying using different surgical gloves and high-tensile strength sutures. Arthrosc J Arthrosc Relat Surg. 2013; 29:1552-8.

[25] Bekele A, Makonnen N, Tesfaye L, Taye M. Incidence and patterns of surgical glove perforations: experience from Addis Ababa, Ethiopia. BMC Surg. 2017; 17:26.

perforations: experience from Addis Ababa, Ethiopia. BMC Surg. 2017; 17:26. [26] Elce YA, Laverty S, Almeida da Silveira E, Piat P, Trencart P, Ruzickova P, et al. Frequency of
Undetected Glove Perforation and Associated Risk Factors in Equine Surgery. Vet Surg. 2016; Undetected

[27] Kumar D, Shantanu K, Kumar M, Kumar A, Sharma V. A Cross-sectional Analysis of Glove Perforation in Primary and Revision Total Hip Arthroplasty. Malays Orthop J. 2016; 10:31-35 [28] Mingoli A, Brachini G, Sgarzini G, Binda B, Zambon M. Needlestick Injuries, Glove Perforation and Round-Tipped Blunt Needles. World J Surg. 2017; 41:2413.

Citation: Medhioub F, Jaber E, Hamrouni A, Gharbi L. Unnoticed surgical gloves intraoperative perforation: A multicentric study of the leading factors. Jr. med. res. 2020; 3(3):9-12. Medhioub et al (C) All rights are reserved. 